\title{
The comparison of topiramate and placebo in the treatment of posttraumatic stress disorder; randomized double blind study Victoria Omranifard*, Shahla Akochekian and Siamak Amanat
}

\author{
Address: Isfahan univercity, Isfahan Noor Hospital, Iran
}

* Corresponding author

from International Society on Brain and Behaviour: 2nd International Congress on Brain and Behaviour

Thessaloniki, Greece. 17-20 November 2005

Published: 28 February 2006

Annals of General Psychiatry 2006, 5(SuppI I):S225 doi:10.1 I86/I744-859X-5-SI-S225

\section{Background}

Based on the kindling hypothesis of PTSD this double blind clinical trial assesses clinical response to Topiramate as a potential treatment.

\section{Materials and methods}

Sixty seven combat veterans with PTSD (30-50 years old $S ; 39.5 \pm 4.19$ ) randomly assigned in a double blind design. They were treated for 12 weeks with Topiramate (n = 33). Measures used in monthly assessments during 3 months of treatment included the clinician-Administered PTSD Scale (CAPS). Paired T-student Friedman and Willcoxon were used to data analysis.

\section{Results}

Three patients were withdrawn from study because of Topiramate side effect. In remainders the mean score of Topiramate group in the first visit was $50.70 \pm 7.7$ and the mean score of placebo group was $48.9 \pm 9.13$. After finishing the treatment period the mean score of the the topiramate group was $32.75 \pm 8.8$. The analysis of these scores showed a significant difference between the groups $(\mathrm{p}=$ $0.00)$. In details: Frequency and intensity of reexperience criteria (intrusive memory nightmare and flash back) sleep problem irritability and anger and frequency of difficulty to recall and intensity of startle reaction in Topiramate group was significantly less than placebo group $(\mathrm{p}<$ $0.05)$.

\section{Discussion}

The results of current study suggest that Topiramate is a safe well tolerate and significantly effective treatment for PTSD.

\section{References}

I. Barlant J, Kammen DP: Open-label topiramate as a primary or adjunctive therapy in chronic civilian post traumatic strss disorder: A preliminary report. J Clin Psychiatry 2002, 63:15-20. 